\title{
A IMPORTÂNCIA DO LABORATÓRIO DE MATEMÁTICA NOS DIAS ATUAIS
}

\author{
Lauriberto Araújo da Silva 1 \\ Jessica da Silva de Araújo ${ }^{2}$
}

RESUMO: O artigo propõe a criação de um LEM (Laboratório de Ensino de Matemática) nas Instituições Públicas Municipais e Estaduais bem como nas Instituições Particulares. O trabalho descreve alguns recursos didáticos e tecnológicos importantes no processo de Ensino e Aprendizagem da matemática principalmente, quanto á forma de ensinar nos dias atuais. Tais recursos como os jogos matemáticos educativos e as TIC's (Tecnologias de Informação e Comunicação) aqui relacionados, mesmo sendo em quantidade mínima servem como parâmetro, para demonstrar o quanto são importantes para o ensino da matemática e, que só podem ser armazenados, em um local apropriado como o LEM. A escola, porém, diz ser desnecessária a criação de um Laboratório por já possuir uma sala de Informática. A verdade é que a escola, não tem o interesse na melhoria do processo de ensino e aprendizagem em matemática pelos alunos e sim, desenvolver projetos, que nunca são elaborados por professores de matemática, para que sejam aplicados nas aulas, mesmo sem trazer ganhos na aprendizagem dos alunos.

Palavras-chave: Matemática. Laboratório de Matemática. Aprendizagem.

ABSTRACT: The article proposes the creation of a LEM (Mathematics Teaching Laboratory) in Municipal and State Public Institutions as well as in Private Institutions. The work describes some didactic and technological resources that are important in the Teaching and Learning process of Mathematics, mainly regarding the way of teaching nowadays. Such resources as educational math games and ICT's (Information and Communication Technologies) listed here, even in a minimal amount, serve as a parameter, to demonstrate how important they are for the teaching of mathematics and, which can only be stored, in a appropriate place like LEM. The school, however, says that the creation of a Laboratory is unnecessary because it already has an IT room. The truth is that the school is not interested in improving the process of teaching and learning in mathematics by students, but developing projects, which are never prepared by mathematics teachers, to be applied in classes, even without bringing gains in the student learning.

Keywords: Mathematics. Mathematics Laboratory. Learnin

\footnotetext{
I Graduado em Licenciatura Plena em Matemática - CIESA - Mestre em Ciências da Educação pela Universidade Del Sol-PY.e-mail: lauriberto_araujo@hotmail.com

2 Graduada em Pedagogia pela UFAM- Especialista em Psicopedagogia - e-mail: jessicasilva.pedagogia@hotmail.com
} 


\section{INTRODUÇÃO}

A proposta deste trabalho é referenciar a importância de um Laboratório de Ensino de Matemática (LEM), para que os alunos se sintam atraídos com a dimensão que o ensino da matemática pode mostrar em um LEM.

O LEM é uma sala diferente das demais por possuírem recursos materiais, pedagógicos, tecnológicos, computacionais de diversos tipos e modelos e que devem estar sempre á disposição dos educadores de matemática e em todas as aulas, para que consigam fazer as demonstrações que aparecem nas explicações, a qualquer momento da aula.

A escola que não possui um LEM nos dias atuais está fadada a continuar com todas as aulas de matemática de maneira totalmente tradicional e sem quaisquer ganhos educativos, quanto ao uso das tecnologias, para as resoluções dos diversos conteúdos matemáticos.

A ideia da criação de um LEM consiste em melhorar os conhecimentos dos alunos, quanto ao uso das tecnologias, nas aulas de matemática.

Busca-se também, melhorar a assiduidade dos alunos nas aulas de matemática, fazêlos compreender sobre a importância tecnológica da matemática bem como, conhecer algumas propriedades que a matemática oferece.

Com o LEM os alunos passarão a gostar mais de estudar matemática, se tornaram pessoas melhores e conseguirão alcançar seus objetivos conseguindo bons empregos.

No LEM, o ensino ocorrerá de maneira mais adequada, muito mais eficiente e muito mais prazerosa tanto para os alunos, que deverão receber os ensinamentos de maneira mais eficaz, quanto aos educadores de matemática poderão exercer suas funções de maneira abrangente com conceitos, demonstrações e propriedades sendo mostradas de modo mais simples do que fazendo, as mesmas explicações, somente se utilizando do quadro branco.

Este artigo, também visa demonstrar as praticidades de um professor de matemática, quando se está trabalhando diretamente em um laboratório de matemática, com tudo ao seu alcance e disposição sem o transtorno de preparar uma aula na sala de informática e, no dia específico, a sala estará ocupada. 
Portanto, este trabalho mostrará a necessidade da utilização de alguns recursos tecnológicos bem como relatará sua eficácia no processo de ensino e aprendizagem da matemática por meio de suas utilizações.

Finalmente, deseja-se que as instituições de ensino das Redes Privadas, Municipais e Estaduais, que tanto descrevem a importância de aulas de matemática melhores, inovadoras e capazes de despertar o interesse do aluno pela escola, que com um Laboratório de Ensino de Matemática bem equipado, produzirá nos alunos, ganhos significativos no processo ensino e Aprendizagem.

Também serão relacionados neste trabalho, alguns elementos essenciais que devem fazer parte do Laboratório de Ensino de Matemática, bem como suas utilizações e eficácia no processo de Ensino e Aprendizagem da Matemática. Pretende-se descrever a importância de se associar determinados conteúdos com suas demonstrações, no mesmo instante em que são dados os determinados conceitos, melhorando ás didático aplicado e facilitando a compreensão imediata dos alunos, diferentemente da sala de aula comum em que os educadores não conseguem fazer algumas demonstrações no quadro.

Este artigo analisará alguns elementos essenciais que deverão fazer parte de um LEM, para que os objetivos desejados possam ser alcançados tais como:

Computadores no Laboratório de Ensino de Matemática para que cada aluno possa utilizá-lo e fazer suas atividades propostas, quando necessárias sem que haja prejuízo á nenhum dos alunos, tendo que esperar um dos colegas terminar para que possa se utilizar. Também, quando forem feitas explicações e os alunos tendo que acompanharem e, irem executando os comandos fornecidos pelo educador de matemática ou, até mesmo, quando forem realizadas avaliações somente com utilização dos computadores.

Material didático específico para o uso do ensino da matemática que possam contribuir no processo ensino aprendizagem e que possam ser manuseados pelos alunos como figuras planas e não planas planificadas e não planificadas, sólidos geométricos.

Jogos matemáticos que contribuam com a aprendizagem dos alunos, capazes de contribuir no processo de ensino e aprendizagem e que possam desenvolver aptidões nos alunos, desenvolver o raciocínio lógico e que sejam capazes de ajudar os educadores diante 
das explicações dadas, bem como desenvolver no aluno, o interesse pelo estudo da matemática.

As TIC's (Tecnologias de Informação e Comunicação), que possuam finalidades específicas no processo de ensino e aprendizagem no ensino da matemática, que contribuam com o ensino proposto pelos educadores de matemática e que possam contribuir no processo social dos alunos. E, para que essas TIC's (Tecnologias de Informação e comunicação) funcionem corretamente, a escola necessita de uma Internet de qualidade que contribua com o funcionamento e realização de todos os recursos tecnológicos que possam contribuir no ensino da matemática, bem como, pesquisas diversas pelo próprio educador de matemática na busca de mais recursos que possam contribuir no processo de ensino e aprendizagem da matemática.

\section{ELEMENTOS ESSENCIAS PARA UM LABORATÓRIO DE ENSINO DE MATEMÁTICA}

\section{I COMPUTADORES NO LABORATÓRIO DE ENSINO DE MATEMÁTCA}

O computador desktop ou notebook é um aparelho no qual boa parte da sociedade utiliza como forma de aperfeiçoar seus trabalhos. "Cada dia mais pessoas estudam em casa, (...), a informação disponível nas redes de computadores interligados a serviços que respondem às suas demandas de conhecimento". (GADOTTI, 2005, p.16). O computador consegue com rapidez desempenhar funções que poderiam demorar muito tempo, se não com sua utilização. Portanto, se torna imprescindível nas escolas.

Quando o professor faz uso do aparelho de computador para auxiliar em uma explicação e, se usa critérios específicos para essa aula de modo que prenda a atenção de seus alunos, associando tais conteúdos com a importância da utilização do computador, o professor estará alcançando alguns objetivos nessa aula.

Figura o6 Laboratório de matemática na Escola Municipal Valter Alencar 


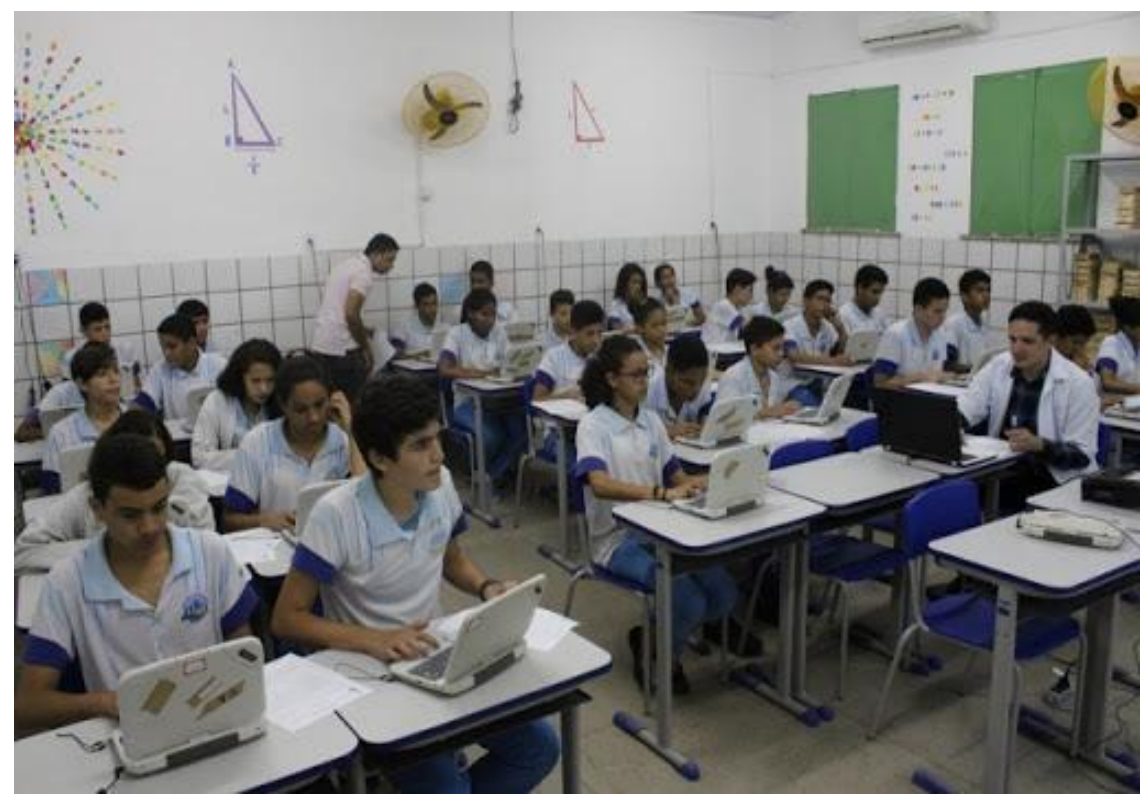

Fonte: ascon / semec-inovação no ensino

O uso do computador em um LEM facilita ás explicações de diversos conteúdos, pois, há uma troca de informações instantâneas. Existe também, o mecanismo das dúvidas e apresentações de dúvidas, de forma muito automática, onde os alunos conseguem de imediato, sanar qualquer que sejam suas dúvidas.

Algumas escolas possuem um laboratório de Informática, mas, que em sua maioria, são computadores ultrapassados, com suas configurações precisando ser atualizadas e, em quantidades insuficientes tendo que disponibilizar um computador para dois ou três alunos.

As escolas precisam ser adequadas não só em relação aos dias atuais, mas também, aos alunos que começam bem cedo, á ter contato com os recursos tecnológicos. É verdade que muitos alunos possuem muito mais conhecimento sobre ás tecnologias que a maioria de seus educadores.

A maioria dos educadores de matemática é cobrada a se atualizarem ou a inseriremse nas aulas com os meios tecnológicos. As instituições de ensino elaboram projetos com a utilização de recursos que a própria escola não possui ou possui de forma irregular como acontece com os computadores que as escolas não possuem ou, se possuem não funcionam adequadamente. 
Então, como os educadores de matemática são cobrados, á desempenharem papeis que na maioria das vezes, não depende do esforço do professor e como, o educador de matemática irá alcançar, os objetivos mínimos desejados, no processo de aprendizagem de seus alunos já que as escolas não contribuem para que esse educador consiga expor suas teorias e demonstrá-las de maneira menos danosa aos seus alunos.

A Escola representada aqui como sendo uma instituição Particular, Municipal e estadual, precisa, com urgência, adequar suas instituições, de maneira que os educadores de matemática possa desempenhar seu papel, o papel de educar e preparar seus alunos para experiências futuras, dispondo á estes educadores, condições para que possam trabalhar principalmente se utilizando de um ambiente virtual. Ou sistema computacional conforme ALMEIDA (2010).

Com a criação de um LEM pela Escola, que seria uma sala diferente das demais, e com acesso exclusivo dos educadores de matemática, a Escola estaria contribuindo para o sucesso desse educador de matemática e principalmente dos alunos. Segundo o que descreve ALMEIDA (2000), o emprego do computador é visto como ferramenta educacional com a qual o aluno resolve problemas significativos. (ALMEIDA, 200o, p. 32).

Neste LEM, que deverá possuir computadores em quantidades mínimas que alcançassem pelo menos uma turma e, que os alunos, não precisassem dividir o aparelho com outro ou, com ouros alunos em uma aula, direcionada exclusivamente para o uso dos computadores, pois, dessa forma, os educadores de matemática, não conseguiriam alcançar seus objetivos em suas aulas, tendo seus alunos, que dividirem esses aparelhos e, portanto, não obtendo assim, seus conhecimentos de forma integral.

Segundo ALMEIDA (200o), o computador por si só, não abrange todos os conhecimentos, nem tampouco, os conhecimentos matemáticos. Para ALMEIDA (200o), o computador funciona diante dos comandos realizados, no caso pelos alunos, para que se obtenham informações desejadas segundo seus interesses.

O computador não é o detentor do conhecimento, mas uma ferramenta tutorada pelo aluno e que lhe permite buscar informações em redes de comunicação a distancia, (...). Tais informações podem ser integradas pelo aluno em programas aplicativos, e com isso ele tem a chance de elaborar o seu conhecimento para representar a solução de uma situação problema ou a implantação de um projeto. (ALMEIDA, 2000, p. 32). 
Os computadores são capazes de acelerar o ensino levando mais experiências ao aluno onde deverão possuir, ao final, conhecimentos além da matemática.

Com os computadores, as atividades de simples memorização, perdem espaço, mas constroem o desenvolvimento do raciocínio lógico. O computador é uma ferramenta que pode auxiliar o professor a promover aprendizagem, autonomia, e criatividade do aluno. Mas, para que isto aconteça é necessário que o professor assuma o papel de mediador da interação entre aluno, conhecimento e computador, o que supõe formação para o exercício deste papel. (MAZZILLI, 1992).

Segundo MAZZILLI (1992), o professor deve fazer seu planejamento prevendo situações que possam ocorrer diante das aulas com auxilio dos computadores.

Segundo os PCN's (1998) (Parâmetros curriculares Nacionais), o professor deve ficar sempre no comando das atividades a serem propostas com a utilização do computador, para que os alunos não se dispersem ou utilizem o computador com outras coisas.

É sempre o professor quem define quando, por que e como utilizar o recurso tecnológico a serviço do processo de ensino e aprendizagem. O professor é sempre responsável pelos processos que desencadeia para promover a construção de conhecimentos, e nesse sentido é insubstituível. (BRASIL, 1998, p. 155).

São os computadores, os grandes responsáveis por inserir aos alunos, e professores, no mundo tecnológico educativo nas aulas de matemática.

Os computadores que irão ajudar á fazer, demonstrações de gráficos, que não podem ser realizadas no quadro.

São os computadores, os responsáveis pelas apresentações diversas, elaboradas pelos alunos.

São os computadores, que irão desenvolver, ou apenas utilizar, os aplicativos disponíveis somente para os desktops.

São os computadores os grandes responsáveis por despertar um interesse maior pela matemática.

São os computadores que irão fazer funcionar o Laboratório de Ensino da Matemática, uma vez que terão diversos aplicativos instalados capazes de tornar mais ágil, as aulas de matemática. 
Os computadores poderão armazenar aplicativos matemáticos facilitadores nas aulas de matemática tais como:
a) Geogebra;
b) Cola Matemátics;
C) iMathematics;
d) Matemática elementar;
e) Myscript Calculator.

\subsection{MATERIAIS DIDÁTICOS}

O LEM deve conter dentre outras coisa, o Material Didático. Esse Material Didático pode ser denominado por um objeto em que o aluno possa manusear como forma de obter conhecimentos matemáticos e sob a orientação de seu professor de matemática.

O material didático é um dos recursos didáticos que o professor pode se utilizar em suas aulas, para facilitar uma explicação determinada, pois tudo que for manipulado pelo estudante, favorece na aprendizagem cognitiva. Tudo aquilo que possa ser utilizado para ensinar, são designados Recursos didáticos. (ZABALA, 1998).

Assim como tudo na matemática, não se deve utilizar o material didático como "pura" distração. Isto pode ser considerado pelo aluno como uma simples brincadeira e, não conseguirá alcançar os objetivos desejados em uma aula específica, diferente, por exemplo, o conteúdo ministrado e o manuseio do material didático.

Dante (2005) descreve a necessidade do professor de matemática desenvolver nos alunos, as habilidades desejadas como objetivos alcançados, afim de esses alunos consigam desenvolver soluções de problemas por meio de deduções lógicas e criativas.

É Preciso desenvolver no aluno a habilidade de elaborar um raciocínio lógico e fazer uso inteligente e eficaz dos recursos disponíveis, para que ele possa propor boas soluções às questões que surgem em seu dia-a-dia, na escola ou fora dela. (DANTE, 2005, P. II).

Esse Material didático deve, dentre outras coisa, também ficar no Laboratório de Ensino de Matemática, pois, poderá ser utilizado por qualquer um dos professores de matemática, não necessitando, porém, que cada educador, possua o seu material Didático individual. 
O Laboratório de ensino de Matemática é acima de tudo, um local de acesso exclusivo para os educadores de matemática que poderão, em conjunto ou não, elaborar junto com seus alunos, alguns dos Materiais didáticos que ficaram á disposição de todos os educadores de matemática, pois, o LEM é uma sala equipada para que os educadores consigam em suas aulas, alcançar os objetivos desejados e com a ajuda dos materiais didáticos.

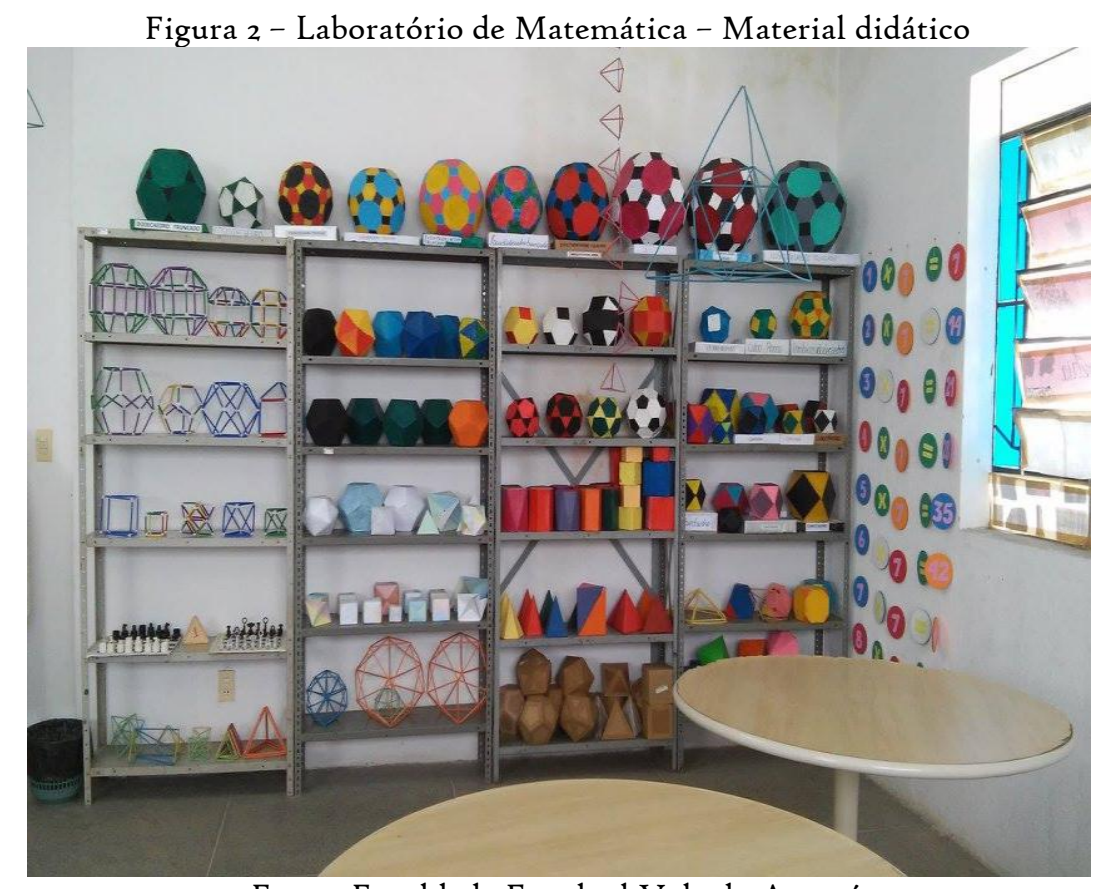

O Material Didático é essencial nas aulas de matemática, pois, facilita o entendimento do aluno fazendo-o entender de maneira significativa. "O importante da ação é que ela seja reflexiva e que o aluno aprenda de modo significativo". (FIORENTINI; MIORIM, 1990).

FIORENTINI; MIORIM ainda descrevem que:

(...), desenvolvendo atividades nas quais raciocine, compreenda, elabore $\mathrm{e}$ reelabore seu conhecimento, sendo que o uso de materiais pode trazer uma grande contribuição nesse sentido. Afinal, o aluno é um sujeito ativo na construção do seu conhecimento; ele aprende a partir de suas experiências e ações, sejam elas individuais ou compartilhadas com o outro. (FIORENTINI; MIORIM, I990, p. $6)$. 
Vale ressaltar, que todo Material Didático necessita de estudos prévios e que, só poderão ser utilizados, quando servirem de complemento de uma aula qualquer contribuindo para o entendimento correto desse material didático com os conteúdos ministrados e sempre comandados por seus educadores de matemática. Daí, a importância de um laboratório de matemática, que tenha disponível aos seus educadores de matemática, recursos didáticos variados e que possam ser utilizados sempre que necessários e estando sempre a disposição do professor, para que sejam feitas as devidas comparações.

Muito diferente de quando o professor planeja uma aula com a utilização de material didático qualquer e, que a cada sala, deverá leva-los consigo acabando sendo danificado muitas vezes, esse material didático, devido ao translado de uma turma para outra, causando o desinteresse desse professor em estar fazendo esse transporte em todas as aulas e, depois de certo tempo, a destruição de alguns, poucos, matérias didáticos existentes.

Qualquer que seja o material Didático utilizado pelo educador de matemática deverá proporcionar aos alunos, no mínimo, o interesse pela descoberta, melhor relacionamento professor e aluno e, o interesse por descobertas nas resoluções dos problemas matemáticos.

\subsection{JOGOS MATEMÁTICOS}

Ensinar matemática sempre foi uma tarefa muito difícil de ser executada pelo mesmo por excelentes educadores de matemática. Isto porque, á grande maioria dos alunos sempre relatam ser esta a disciplina que menos gostam. E como fazer algo que não gosta, e como estudar uma disciplina, que na maioria das vezes os alunos á desconhecem. Como criar entusiasmo nos alunos para que gostem de estudar matemática.

Os alunos já chegam sua vida escolar, com essa ideia de que o professor de matemática é Mau ou, que a matemática é muito difícil e que eles não irão aprender.

O aluno quando inserido em um LEM, começa á perceber uma realidade diferente daquela idealizada por ele durante muitos anos, pois, verifica ali, vários materiais didáticos e logo ficam surpreendidos. 
Quando o professor começa suas explicações e os direciona aos computadores, neste momento, eles percebem que a matemática é muito diferente do que eles haviam idealizado durante muito tempo.

Essa situação não ocorre nas salas de aula, pois, quando o professor de matemática entre para lecionar para estes mesmos alunos em uma sala comum, o professor logo se dirige ao quadro para começar suas explicações.

Os jogos matemáticos possuem o poder de aumentar a autoestima dos alunos, pelo simples fato de saberem que á aulas de matemática será no computador. E quando associadas, essas aulas á jogos matemáticos, os alunos percebem que a matemática pode ser divertida

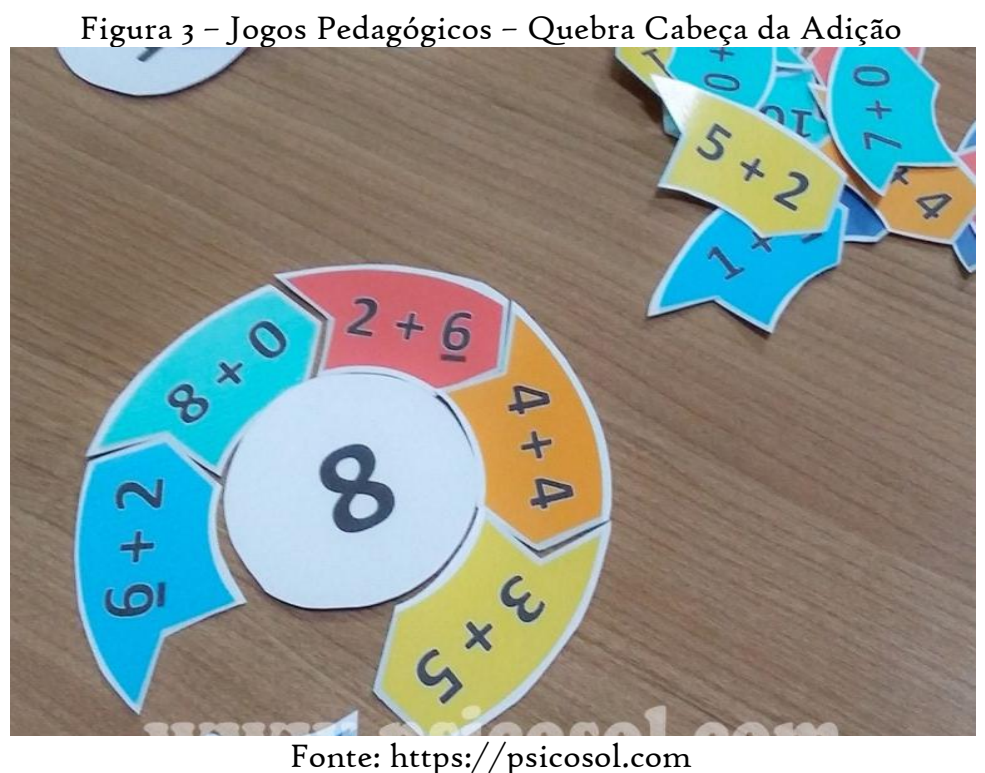

Os jogos matemáticos devem ser administrados pelos educadores de matemática $\mathrm{e}$ sempre intermediando a aplicação do jogo para que se consigam alcançar os objetivos desejados já que será um complemento do conteúdo.

Cabe ao educador de matemática sempre disponibilizar os jogos que podem ser inseridos em suas aulas como complemento didático.

Segundo BORIN (1996), os alunos quando são induzidos ao estudo da matemática com atribuições de jogos matemáticos, despertam um tipo de euforia, por parte de alguns 
alunos, resultando em diminuição de certos bloqueios que estes alunos possuem tanto na disciplina matemática quanto ao seu professor de matemática. (BORIN 1996).

\footnotetext{
Outro motivo para a introdução de jogos nas aulas de matemática é a possibilidade de diminuir bloqueios apresentados por muitos de nosso estudante que temem a Matemática e sentem-se incapacitados para aprendê-la. Dentro da situação de jogo, onde é impossível uma atitude passiva e a motivação é grande, notamos que, ao mesmo tempo em que estes alunos falam Matemática, apresentam também um melhor desempenho e atitudes mais positivas frente a seus processos de aprendizagem. " (BORIN, 1996, P. 09).
}

Existem vários jogos matemáticos que podem ser escolhidos de acordo com as idades dos alunos, tais como:

a) Jogo da memória; estimula o raciocínio lógico;

b) Jogo de tabuleiro: estimula as estratégias;

C) Jogo de dominó: estimula a soma;

d) Jogo de formas geométricas: trabalha elementos geométricos;

e) Jogo dos polígonos: trabalha o conhecimento de polígonos.

Além de uma quantidade muito grande de outros jogos matemáticos, aplicativos e softwares matemáticos, materiais didáticos, recursos tecnológicos que só em um LEM, que possui estrutura capaz de armazenar todas estas informações e que estejam ao alcance dos professores e alunos para que o ensino seja de qualidade.

Quando o jogo matemático é elaborado para acrescentar nas explicações do professor de matemática, esses jogos são capazes obter resultados, muitas vezes, além do esperado, pois, se trata de um recurso pedagógico eficaz.

Mas, se faz necessário, que as Escolas nas modalidades Particular, Municipal e Estadual analisem o ensino da matemática como uma disciplina difícil e diferenciada e, portanto, que precisa ser trabalhada como fonte inspiradora na busca de conhecimentos matemáticos.

Os jogos matemáticos são capazes de desenvolver uma aprendizagem significativa por serem estudos divertidos. Mas, não significa que em todas as aulas de matemática serão por meio de jogos.

O professor que é quem deve intermedias os jogos específicos e associados aos conteúdos estudados, que ora, já deveram ter sido trabalhados em sala anteriormente ou 
para iniciar os conteúdos matemáticos que serão inicializados em sequência. "Nada deve ser dado á criança, no campo da matemática sem primeiro apesentar-se a ela uma situação concreta que a leve a agir, a pensar, a experimentar, a descobrir, e daí, mergulhar na abstração". (FIORENTINI e MIRIOM, 2004, p. oi).

Os jogos matemáticos quando aplicados na sala de aulas comum, não apresentam resultados satisfatórios como oferecem os jogos realizados em um LEM.

Os jogos podem ser trabalhados nas aulas de matemática tanto na forma física (manipulação de figuras planas, por exemplo), mental (quando é utilizado cálculo mental, raciocínio lógico), de tabuleiros (dominó jogo das operações ou das frações), eletrônicos (jogos de computador), e aplicativos (uso das tecnologias).

Porem, todos estes jogos só deve ser aplicado, nas aulas de matemática, quando necessitarem de alguns complementos para que a aprendizagem aconteça.

A aprendizagem matemática, quando feita por meio de jogos matemáticos acaba sendo tomada pelos alunos com sendo uma aprendizagem significativa e dada por um processo mais interessante, no ponto de vista do aluno, pois, as aulas se tornam mais participativa e mais divertida. Os jogos acabam se tornando parte integrante nas aulas de matemática. (STAREPRAVO, 2010, P. 20).

[...] Se conseguirmos compreender o papel que os jogos exercem na aprendizagem de matemática, poderemos usá-los como instrumentos importantes, tornando-os parte integrante de nossas aulas de matemática. Mas devemos estar atentos para que eles realmente constituam desafios. Para isso, devemos propor jogos nos quais as crianças usem estratégias próprias e não simplesmente apliquem técnicas ensinadas anteriormente. (STAREPRAVO, 2010, P. 20).

Os conceitos matemáticos podem, facilmente, ser assimilados pelos alunos, quando são utilizados por meio de jogo matemáticos. Os jogos matemáticos funcionam como uma forma de desafio á eles, pois estão bem adaptados há pequenos recursos tecnológicos o que lhes favorecem e os estimulas nas resoluções de problemas matemáticos através dos jogos matemáticos.

A prática do educador de matemática em ensinar, principalmente conceitos matemáticos, por meio de jogos, sejam eles práticos ou com manuseio de um aparelho eletrônico deve estar atrelada aos seus planejamentos e, principalmente, se planejar para aplicações de jogos na sala de aula comum ou na sala de informática, contando com os 
imprevistos de já estar sendo ocupada ou, até mesmo, fazer seu planejamento para trabalhar com seus alunos, em um laboratório de matemática.

Todos os procedimentos tornam-se muito mais simples, quanto ao uso de jogos matemático, quando produzidos, revisados e executados no LEM. O professor deve priorizar jogos matemáticos principalmente, quando os conteúdos forem mais complicados.

\subsection{AS TIC'S (TECNOLOGIAS DE INFORMAÇÃO E COMUNICAÇÃO)}

As instituições de Ensino devem propiciar condições aos alunos e educadoras para que possam crescer de forma educacional e tecnológica. $\mathrm{O}$ ambiente virtual propicia mais recursos. (MORAN, 2013).

Segundo MORAN (2013), A escola é o local onde os alunos gostariam de estar, deveria ser um ambiente agradável que oferecesse condições aos alunos de aprendizagens inclusive tecnológicas, de informação e comunicação, que fornecesse recursos que melhorariam seus conhecimentos na escola ou fora dela.

O que realmente os educadores de matemática necessitam é a criação de um Laboratório de Ensino de Matemática, local este, destinado ao uso exclusivo aos educadores de matemática. Em um LEM, com os equipamentos necessários, incluindo uma internet de qualidade, seria algo que a Escola poderia fazer para que os educadores de matemática desempenhassem um trabalho com mais qualidade e objetividade.

Para CARMO (2010) é na escola que o aluno passa a maior parte de seu tempo, quando não estão em suas casas e, portanto, deveria oferecer um ambiente com condições que lhes permitissem seu crescimento na escola e para os dias atuais, ganhos tecnológicos. O local para ocorrer o estudo é fundamental, "condições ambientais que permitam a interação e o uso do procedimento de ensino". (CARMO, 2010, P. 20).

Realmente, com os sucessivos ganhos tecnológicos voltados também para o ensino da matemática, os educadores desta disciplina poderiam diversificar um pouco em suas atuações. Mas, a Escola, de forma geral, não se habilita de maneira correta ou demora muito tempo para se adequar ás inovações para o ensino. 
A Escola deve, sobretudo, disponibilizar o acesso aos recursos tecnológicos, á todos os alunos, para que não fique restrita somente á alguns alunos com pouco mais de recursos. “a escola deve facilitar o acesso das comunidades carentes ás novas tecnologias". (PRETTO, 1999, P. 104).

As TIC's (Tecnologias de Informação e Comunicação) possuem grandes recursos tecnológicos disponíveis, para que o educador de matemática, possa se utilizar em suas aulas. Mas, são recursos tecnológicos que, necessitam prioritariamente da utilização dos computadores e da internet.

E, é a Escola, quem deve oferecer estes recursos, aos seus educadores. Estes recursos serviriam como apoio á explicações dadas ou até mesmo, serviriam como explicações.

Essas TIC's ajudariam em explicações mais complexas que demandariam de muito tempo, para serem explicadas diretamente no quadro e, em certos casos, com muito mais precisão e efeitos e muito mais qualidade que estas mesmas aulas teriam em uma sala comum.

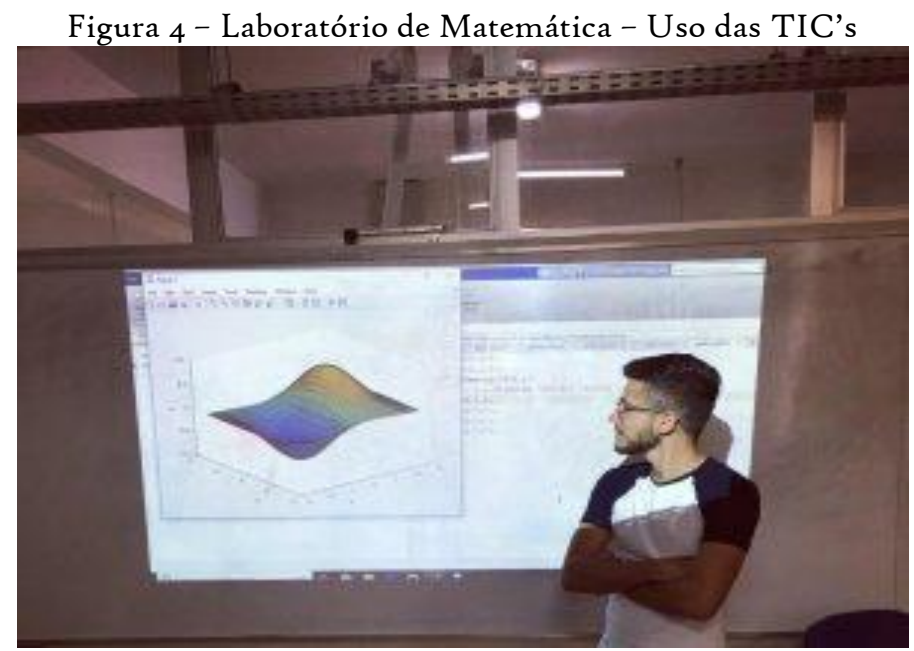

Fonte: Unifap - III Seminário de História da Matemática e ensino

Na figura pode observar uma imagem Segundo HALLBERG e LISBOA (2016), as TIC's, quando empregadas em locais adequados e compostos não só de infraestruturas, mais por equipamentos capazes de reproduzir as informações desejadas, são capazes de mudar o comportamento e interesse dos alunos.

Para HALLBERG e LISBOA (2016), as Tecnologias de Informação e Comunicação são; 
Um conjunto de dispositivos, serviços e conhecimentos relacionados a uma determinada infraestrutura, composta por computadores, softwares e sistemas de redes, os quais possuem a capacidade de reproduzir, processar e distribuir informações para pessoas e organizações. (HALLBERG e LISBOA, 2016, p. 2).

O LEM traria ao educador de matemática, uma certeza quanto á utilização de qualquer recurso didático por estarem sempre á disposição, pois, serão armazenados neste ambiente, que seria um local de uso unicamente dos educadores de matemática.

Diferentemente da sala de informática, local este utilizados por todos os educadores, e que na maioria das vezes, alguns professores já fazem reservas para toda semana ou até o mês inteiro.

O ensino da matemática não é uma disciplina como ás outras, pois, a cada aula, novas explicações e não faz sentido levar os alunos para a sala de informática dois, três dias, ás vezes até mais, depois que finalizados os conteúdos e iniciados outros. Isto não faz sentido principalmente aos alunos que ficam confusos e sem intender porque não foi realizada tal aula, no mesmo dia em que foram ensinados tais conteúdos.

POLATO (2009) descreve o quanto já é difícil, o convívio sem as tecnologias de Informação e Comunicação (TIC) e que os próprios educadores, ainda possuem dificuldades em assimilar, esses avanços tecnológicos e que, também podem ser inseridos em suas aulas de muitas maneiras. Mas, estes educadores também sabem que não depende somente deles, como a Escola demonstra diariamente, mais sim da Escola, quanto á infraestrutura e aquisição de equipamentos adequados.

[...] TICs, tecnologias da informação e comunicação. Cada vez mais parece impossível imaginar a vida sem essas letrinhas. Entre os professores a disseminação de computadores, internet, celulares, câmeras digitais, e-mails, mensagens instantâneas, banda larga e uma infinidade de engenhocas da modernidade provocam reações variadas. [...] [Porém] a relação entre a tecnologia e a escola ainda é bastante confusa e conflituosa. (POLATO, 2009, P. 50).

As TIC's possuem diversos recursos que o professor de matemática pode se utilizar-se em suas aulas como forma de complementar suas explicações que no quadro, não seriam possíveis. 


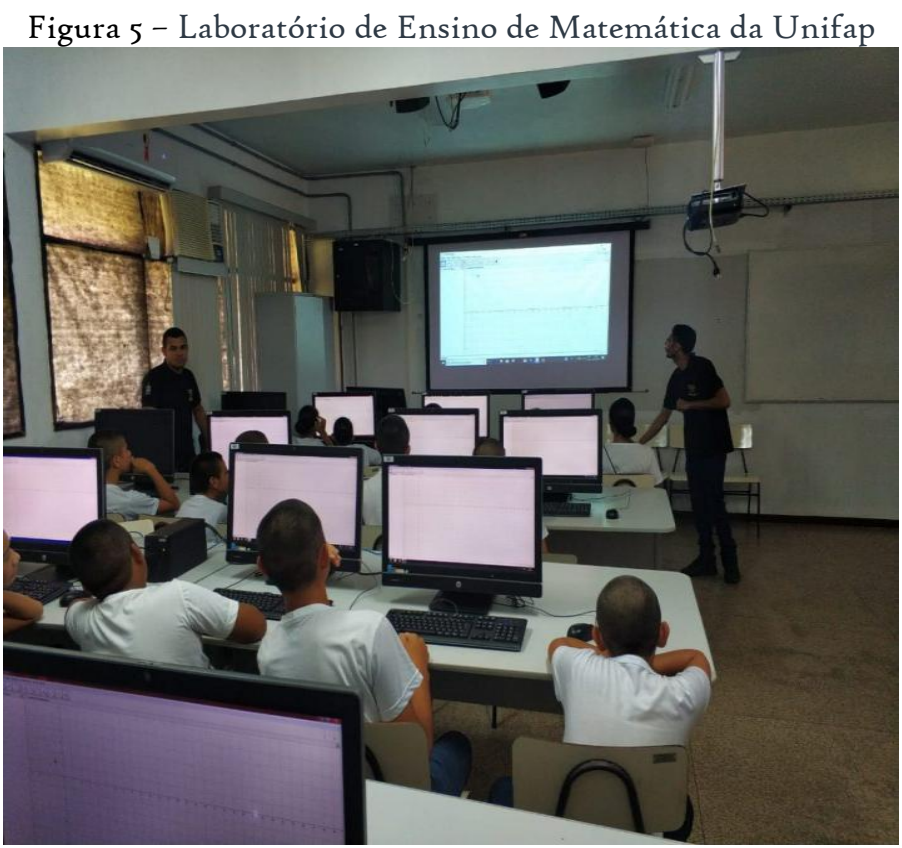

Fonte: III Seminário de História da Matemática e ensino Uso das TIC's

As TIC's conseguem ajudar os educadores de matemática á facilitar suas explicações, ou até mesmo, mostrar algumas demonstrações de forma mais rápida e eficaz.

Essas Tecnologias de Informação e Comunicação podem mostrar figuras em outras dimensões até então, impensáveis pelos educadores de matemática, e que nunca conseguiriam demonstrá-las em suas aulas no quadro.

Essas As TIC's são todas as possibilidades encontradas e que possam ser utilizadas por um computador ou celular sejam com softwares específicos para o ensino da matemática, jogos matemáticos, aplicativos e tudo aquilo que possa ser pesquisado com o auxilia da Internet.

Segundo BORBA (20oI) o uso da informática como um recurso tecnológico é considerada uma mídia alternativa e que pode reorganizar a forma de pensamento.

A utilização da internet na escola motiva muito mais os alunos e ajuda no desenvolver de competências. (MORAN, 2007).

Segundo CAMMAS (2013), as tecnologias de informação digitais proporciona a implantação de técnicas na escola com orientações específicas do professor. 
Há uma preocupação muito grande quanto á incorporação das TIC's, principalmente nas escolas e com a adesão dos educadores. Sabe-se que não é uma tarefa simples, mas, se não houver um começo irá sempre ficando adiado este projeto. Não se trata de dizer que a escola possui computadores e internet. $\mathrm{Na}$ educação e em especial á educação matemática, esses procedimentos vão muito além de um simples computador ou uma internet que funciona precariamente. As mudanças acontecem e geram transformações nos processos de comunicação de educação e aprendizagem. (SANTOS, 2006, P. 123).

As Escolas devem priorizar a incorporação das tecnologias na educação matemática, mais propiciando condições para estes educadores, de modo que consigam se aperfeiçoarem diante dessas TIC's para que consigam, além de compreender o uso das Tecnologias de Informação e Comunicação, consigam ministrar suas aulas com a utilização dessas TIC's.

Os PCN's (Parâmetros Curriculares Nacionais) também destacam que os recursos tecnológicos dentre outras coisas podem: Permite que os alunos construam uma visão mais completa da verdadeira natureza da atividade matemática e desenvolvam atitudes positivas diante de seu estudo. (BRASIL, 1998, p. 43-44).

Segundo os PCN's (1998), os recursos tecnológicos possuem á capacidade de desenvolver nos alunos, mais interesse pelo estudo em geral para que obtenham o desenvolvimento de sua aprendizagem.

\section{CONSIDERACOES FINAIS}

Está evidente que os profissionais da educação necessitam de um amplo apoio por parte da Escola em se aperfeiçoarem e se adequarem, quanto ás tecnologias que estão disponíveis no universo acadêmico.

Essa pesquisa demonstrou o quanto nossos alunos precisam de mais motivação $e$ que com o empenho dos educadores de matemática em um LEM, as angustias tanto de alunos, quanto de professores, serão minimizadas diante dos recursos que só um LEM pode oferecer.

Também foram descritos alguns materiais didáticos importantes no processo de ensino e aprendizagem dos alunos e que são em quantidades muito grandes que um 
educador. Não consegue transportar de uma sala para outra o tempo todo, mesmo porque o professor atua em turmas diferentes e teria que parar para trocar porque as aulas seriam diferentes e precisariam ou não da utilização desses materiais didáticos.

Todos os objetivos que deveriam ser alcançados tiveram êxito com ás aulas em um LEM bem como uma maior participação e assiduidade dos alunos.

O presente artigo demonstrou que a inclusão dos recursos didáticos como ás aulas em computados, por meio de jogos, com a utilização dos materiais didáticos disponíveis e principalmente com a utilização das TIC's que conseguiram apresentar imagens inimagináveis em um quadro branco.

Por fim, foram apresentados resultados que comprovaram á importância e necessidade de um LEM nas escolas, mas, que os resultados, não pareceram suficientes para o convencimento das Escolas e que é suficiente, apenas á continuidade de apresentação de projetos como forma de melhorar o conhecimento dos alunos no ensino da matemática.

Os próprios educadores ficaram muito entusiasmados com a ideia da criação do LEM, pois, teriam ali, opções de acrescentarem em seus planos, outros mecanismos de ensino que tornariam á aprendizagem, muito mais significativa.

O LEM dentre diversos ganhos proporcionados á Escola poderia oferecer ao educador de matemática, á obter os conhecimento necessário quanto ao manuseio dos aparelhos de computador e das TIC's.

O LEM além de desenvolver o interesse no aluno quanto ao ensino da matemática poderia, com o tempo, aumentar, mais e mais o interesse desses alunos, em permanecer na escola, pois, lhes seriam proporcionados aulas mais interessante, com demonstrações de conteúdos, que no quadro não conseguiriam entender, e passariam não só á gostar de matemática, mais em aprender esta disciplina tão interessante e tão importante para estes alunos e para seus futuros.

Parte dos Materiais Pedagógicos manuseáveis seria confeccionada, pelos próprios alunos e deixados no laboratório para que fossem utilizados por todos que ali adentrassem o que causaria certa satisfação aos alunos que confeccionassem tais matérias Pedagógicas. 
A Escola que possui um Laboratório de Ensino de Matemática apresentam grandes resultados, por parte daqueles alunos que o frequentam, em pesquisas diversas.

Portanto, a Escola precisa, com certa urgência, colocar em prática, tudo que escreve e deseja que sejam alcançados pelos educadores de matemática, criando um Laboratório de Ensino de Matemática em suas instituições de ensino e, dando oportunidade aos alunos, de conhecerem mais afundo á matemática e suas funcionalidades, pois só no quadro branco, em uma sala de aula comum, isso seria improvável.

\section{REFERENCIAS}

ALMEIDA, M. E. Informática e formação de professores. Brasília: MEC, 2000 (vol. i e 2).

BORBA, M. C. Coletivos seres-humanos-com-mídis e a produção de Matemática. In: Simpósio Brasileiro de Psicologia da educação Matemática, I, 200I,

BORIN, J. Jogos e resolução de problemas: uma estratégia para as aulas de matemática. São Paulo: IME-USP, 1996.

BRASIL, Secretária de Educação Fundamental. Parâmetros curriculares nacionais: matemática. Brasília: MEC, 1998.

CAMAS, N. P. V. MANDAJI, M. RIBEIRO, R. A. MENGALLI, N. M. Professor e Cultura Digital, reflexão acerca dos novos desafios na ação formadora para nosso século. Revista Reflexão e Ação. v. 21 n. 2 p.179-198. Santa Cruz do Sul: UNISC, 2013.

CARMO, J.S. Fundamentos psicológicos da educação. - Curitiba: Ibpex, 2010. - (Séries Psicologia em Sala de Aula).

DANTE, L. R. Didática da Resolução de Problemas de Matemática. ${ }^{\underline{a}}$ a $5^{\underline{a}}$ séries - $12^{\underline{a}}$ ed., Ática, 1999.

FIORENTINI, D. MIRIOM, M. Â. Uma reflexão sobre o uso de materiais concretos e jogos no Ensino da Matemática. São Paulo: UNICAMP, 2004.

FIORENTINI, D.; MIORIM, M. A. Uma reflexão sobre o uso dos materiais concretos e jogos no ensino da matemática. Boletim da Sociedade Brasileira de Educação Matemática, São Paulo: SBEM-SP, n.7, p. 5-10, 1990.

GADOTTI, M. Boniteza de um sonho: Ensinar-e-aprender com sentido. Curitiba PR: Ed. Positivo, 2005. 
HAlLBERG, S. C. M.; LISBOA, C. S. M. Percepção e Uso de Tecnologias da Informação e Comunicação por Psicoterapeutas. In: Revista Trends in Psychology / Temas em Psicologia. Ribeirão Preto: Vol. 24, no 4, p. or - 50 Dez. 2016. Disponível em: http://pepsic.bvsalud.org/pdf/tp/v24n4/v24n4ao6.pdf. Acesso em: I2 de novembro. 2020.

MAZZILLI, S. A. pedagogia além do discurso. Piracicaba: UNIMEP, 1992.

MORAN, J. M. MASSETO, M. T. BEHRENS, M. A. Novas tecnologias e mediação pedagógica. 21. ed. Campinas: Papirus, 2013.

MORAN, J. M. A educação que desejamos novos desafios e como chegar lá. Campinas: Papirus, 2007.

POLATO, A. Tecnologia + conteúdos = oportunidades de ensino. Revista Nova Escola, São Paulo, n. 223, p. 50, jun./jul. 2009.

PRETTO, N. DE L. Globalização \& organização: mercado de trabalho, tecnologias de comunicação, educação à distância e sociedade planetária. Ijuí: Ed. Unijuí, 1999 .

SANTOS, E. O; ALVES, L. Práticas Pedagógicas e Tecnologias Digitais. Rio de Janeiro: E-papers, 2006.

STAREPRAVO, A. R. Jogos, desafios e descobertas: o jogo e a matemática no ensino fundamental - séries iniciais. Curitiba: Renascer, 1999.

ZABALA, A. A prática educativa: Como ensinar. Porto Alegre: Editora Artes Médicas Sul Ltda. (1998) 